\section{SECTION ON NEUROLOGY AND MEDICAL JURISPRUDENCE.}

Chairman, Dr. Harold N. Moyer, Chicago, Ill.

Secretary, Dr. Geo. R. Trowbridge, Danville, Pa.

The Section met in the hall of the Young Men's Christian Association, Detroit, at 3 г. M., June 7, 1892, and was called to order by the chairman.

In the absence of the secretary, Dr. Trowbridge, Dr. W. J. Herdman, of Ain Arbor, Mich., was elected secretary pro term.

1. The first order of business was remarks by the chairman of the Section, Dr. Moyer.

2. Paper by MIr. Henry A. Chaney, with discussion.

3. Paper by Dr. Comegys, with discussion.

4. Paper by Dr. Hughes, with discussion.

5. Paper by Dr. Mills, with discussion.

6. Paper by Dr. Kiernan.

7. Paper by Dr. Chaddock, with discussion.

8. Papers by Drs. Rockwell and Fell, with joint discussion.

9. Paper by Dr. Howell, with discussion (paper not received).

10. Paper by Dr. Sanger Brown, with discussion.

11. Papers by Drs. Bremer and Lydstur, with discussion.

12. Paper by Dr. Fuller.

13. Paper by Dr. Manley, with discussion.

14. Papers by Drs. Crothers, Dewey and Talbot, with discussion.

The following papers read by title:

1. Paver by 10r. Moyer.

2. Paper by Dr. Wright.

3. Paper by Dr. Mason.

4. Paper by Dr. Norbury.

\section{REMARKS BY THE CHAIRMAN.}

BY HAROLD N. MOYER, M.D., OF CHICAGO.

Gentlemen: The address which I had prepared on the organization of the work of this Section is no longer suitable. I had outlined in that address what I conceived to be the best organization to the end that we should develop our own autonomy to some extent on the lines adopted by the Section on Ophthalmology. But the action of the Association this morning in creating an Executive Committee for the Sections, and giving it power to formulate some general rules for the conduct of the Association in the future, has made my address somewhat inappropriate; therefore, I will not deliver it, but instead will briefly refer to a few points of an historical nature.

It was many years since Dr. Ray instituted a section on insanity in the Amerucan Medical Association, which was continued for some years and did good work. For some reason that section was finally discontinued and its work was merged into the Sec. tion on the Practice of Medicine. Thus, for a number of years-at least, more than a dozen-there was no special section for the discussion of neurological subjects.

In 1884, Dr. Quimby, I think, introduced a resolution creating a Section on Medical Jurisprudence. The following year this Section was instituted, and the Section held its first meeting in Cincinnati. We had then some six papers on the program and about four or five members to listen to them.

The following year the scope of the Section was enlarged by the addition of neurology, and at the Nashville meeting we had a fair attendance and a few excellent papers. The next meeting at Washington showed renewed interest in the work of this Section, twenty-two papers were read, and the attendance was large. From these small beginnings the work has gradually developed until we present you to-das a program containing forty-one titles, many of them from the pens of the most eminent neurologists in this country.

I think we can congratulate ourselves on the success of the work of our Section; one of the youngest, it has shown a vitality and growth that has in some cases outstripped its elders. I feel that without making invidious distinctions that I can especially mention the enthusiastic work of Drs. Hughes, Kiernan, Crothers, and Evarts. It is due largely to the persistent work of these men that we have achieved such a signal success; with such a past we can confidently look forward to the near future when the meeting of this Section will show as good work as is done by any similar body in this country. (Applause.)

\section{RESPONSIBILITY IN WILL-MAKING.}

Read in the Section of Neurology and Nedica I Jurisprudence, at the Forty-tuird annual meeting of the American Medical Association,
held in Detroit, Mich., June 7,1892 .

BY IIENRY A CHANEY OF DETROIT, MICH.

PROFESSOR OF MEDICALJURISPUDENCE, MICHIGAN COLLEGE OF MEDICINE A ND SURGERY.

It is and has long been the all but universal rule that one must be of sound mind to make a will that will stand. It is so laid down in the statutes of nearly all the States. If this rule were rigidly observed, many more wills would be set aside than are. But the courts have greatly relaxed it, so that absolute soundness of mind is now by no means a condition to the making of valid bequests. The old English law was that a single foolish word would spoil a will, and so recent a chancellor as Lord Brougham decided that any degree of mental perversion would be fatal. But when Sir Alexander Cockburn came to the bench, he changed the whole current of the English law on that point. In the case of Banks $v$. Goodfellow, 5 Q. B. 549 , he stated in the clearest and most positive way the then existing rule and the reasoning that supported it. The rule was, that any degree of mental unsoundness, however slight, and even though it exercised no influence on the will and was wholly unconnected with the disposition the testator made of his property, was fatal to the will. And the reason was that the mind, though it has various faculties, is one and indivisib]e; if it is disordered in any one of these faculties -if it labors under any delusion arising from such disorder, though its other faculties and functions remain undisturbed, it cannot be said to be sound; such a mind is unsound, and testamentary incapacity is the necessary consequence. By way of answer to this, Sir Alexander reviewed in an elaborate opinion the condition of British and Continental jurisprudence on this point, and found it either unsatisfactory or superficial. Turning, then, to the American decisions, and especially to certain New Jersey cases, he commended the good sense of the American law, and said in his own convincing fashion, that if it were conceded that the only legitimate ground for denying testamentary capacity to persons of unsound mind is their inability to take into account and give due effect to the considerations which ought to be present to the mind of a testator in making his will, and to influence his decision as to the disposal of his property, it follows that a degree or form of unsoundness which neither disturbs the exercise of the faculties necessary for such an act, nor is capable of influencing the result, ought not to take away the power 